\title{
Analysis of X-ray structure, dielectric properties and AC conductivity of (4E)-2-amino-3-cyanobenzo[b]oxocin-6-one
}

\author{
H.A.M. Ali ${ }^{1, *}$, MAGDY A. IBRAhIM ${ }^{2}$ \\ ${ }^{1}$ Physics Department, Faculty of Education, Ain Shams University, Roxy 11757, Cairo, Egypt \\ ${ }^{2}$ Chemistry Department, Faculty of Education, Ain Shams University, Roxy 11757, Cairo, Egypt
}

The crystal structure of (4E)-2-amino-3-cyanobenzo[b]oxocin-6-one, denoted as 4(E)-ACBO, was analyzed using X-ray diffraction technique. The dielectric and AC electrical conductivity measurements of the bulk 4(E)-ACBO in the form of pellet were studied in the range of frequency $42 \mathrm{~Hz}$ to $5 \mathrm{MHz}$ and the temperature range of $303 \mathrm{~K}$ to $373 \mathrm{~K}$. The temperature and frequency dependence of dielectric constant $\left(\varepsilon_{1}\right)$, dielectric loss $\left(\varepsilon_{2}\right)$ and AC electrical conductivity $\left(\sigma_{\mathrm{AC}}\right)$ were investigated. The relaxation time $(\tau)$ for electrons to hop over a barrier of height $\mathrm{W}_{\mathrm{H}}$ was calculated at different temperatures. The $\mathrm{AC}$ activation energy was determined from the temperature dependence of $\sigma_{\mathrm{AC}}$ at different frequencies.

Keywords: chromone derivative; $X$-ray structure; dielectric properties; AC conductivity

(C) Wroclaw University of Technology.

\section{Introduction}

Chromones constitute one of the major classes of naturally occurring compounds [1]. They are oxygen-containing heterocyclic compounds with a benzo-annelated $\gamma$-pyrone ring [2]. Substituted chromones have become attractive targets in organic synthesis because of their significance in biological systems and wide occurrence in natural products [3]. The chemical reactivity of substituted chromones, towards nucleophiles, was studied in details and variable heterocyclic systems were obtained depending on the nature of the functional group present in the $\gamma$-pyrone ring at position 3 and the reaction conditions [4-8].

However, reports on the electrical and photophysical properties of chromone derivatives are limited and there are only few studies on optical and electronic properties, as well as potential applications of chromone derivatives in the functional devices [9]. The study of the electrical conduction and its mechanisms in organic compounds has been a subject of many theoretical and experimental investigations. The interest in this topic is

*E-mail: hend2061@yahoo.com stimulated by the applications of these compounds in the development of various modern and future technologies of solid-state devices [10]. Charge transport measurements in semiconductors and insulators can provide valuable information about the electronic structure of these materials [11]. The electrical measurements performed via direct current, DC, and alternating current, AC, techniques on organic materials and related devices are essential for characterizing both the material and device properties. The study of the effects of frequency and temperature on the AC conductivity offers a lot of information about bound (localized) electric charge carriers. This leads to good explanation and understanding of the electric and dielectric behavior of organic semiconductors [12].

The present work aimed to investigate the crystal structure of the powder of the (4E)-2-amino-3cyanobenzo[b]oxocin-6-one, (4(E)-ACBO) using $\mathrm{X}$-ray diffraction technique for the first time. The dielectric properties and $\mathrm{AC}$ electrical conductivity were analyzed for the bulk (4(E)-ACBO). The temperature and frequency dependence of dielectric constant, dielectric loss and AC electrical conductivity measurements of the bulk 4(E)-ACBO in a form of a pellet, were carried out for the first time. 
The range of frequency was $42 \mathrm{~Hz}$ to $5 \mathrm{MHz}$ and the temperature range was $303 \mathrm{~K}$ to $373 \mathrm{~K}$.

\section{Experimental}

All chemicals were obtained from Sigma Aldrich Company and used without further purification. All melting points of the investigated materials were recorded in open capillary tubes on a Stuart SMP3 melting point apparatus. Infrared spectra were recorded on FT-IR Bruker Vector 22 spectrophotometer using the $\mathrm{KBr}$ wafer technique. 4(E)-ACBO was synthesized by ring transformation of chromone derivatives [13]. In our synthesis chromone was used as a starting material. A mixture of chromone (1) $(0.73 \mathrm{~g}, 5 \mathrm{mmol})$ and malononitrile $(0.33 \mathrm{~g}, 5 \mathrm{mmol})$ in absolute ethanol $(10 \mathrm{~mL})$ containing few drops of triethylamine was heated under reflux for $30 \mathrm{~min}$. The orangered crystals obtained during the heating were filtered and recrystallized from $\mathrm{DMF} / \mathrm{EtOH}$ to give the compound (2) in a form of orange-red crystals, melting point in the range of $277^{\circ} \mathrm{C}$ to $278{ }^{\circ} \mathrm{C}$ (the value $278^{\circ} \mathrm{C}$ was given in the literature [13]).

$\mathrm{X}$-ray diffraction pattern (XRD) for the powder of 4(E)-ACBO was detected using Philips X-ray diffractometer (model $X^{\prime}$ pert) operated at $40 \mathrm{kV}$ and $25 \mathrm{~mA}$ in the $2 \theta^{\circ}$ angle range from $4^{\circ}$ to $60^{\circ}$ with use of monochromatic $\mathrm{CuK} \alpha$ radiation.

For dielectric and AC conductivity measurements, the sample was fabricated in the form of $\mathrm{Ag} / 4(\mathrm{E})-\mathrm{ACBO} / \mathrm{Ag}$ sandwich structure. The powder of 4(E)-ACBO was ground to obtain very fine particles and pressed in a form of a pellet of a thickness $0.75 \mathrm{~mm}$ using a suitable pressure of $2 \times 10^{8} \mathrm{~Pa}$. Silver electrodes were deposited onto both sides of the pellet by thermal evaporation technique in a vacuum of $10^{-4} \mathrm{~Pa}$ by using a high vacuum coating unit (Edwards, E306A). A programmable automatic RLC bridge, model Hioki 3532-50 Hitester, was used for the measurements. The sample was placed in a holder specially designed to minimize stray capacitance. The range of frequencies was $42 \mathrm{~Hz}$ to $5 \mathrm{MHz}$. The temperature of the sample was measured by a Chromel-Alumel thermocouple over a temperature range of $303 \mathrm{~K}$ to $373 \mathrm{~K}$.

\section{Results and discussion}

The chemical reactivity of chromone was previously studied towards some primary and secondary amines, no reactions were carried out with carbon nucleophiles. The chemical transformation of chromone moiety into malononitrile was studied and the characterizations of the synthesized product were performed. Chromone (1) possesses two electron deficient centers $\mathrm{C}-2$ and $\mathrm{C}-4$ as $\mathrm{C}=\mathrm{O}$. The $\mathrm{C}-2$ position is more electron deficient and reacts more rapidly with nucleophiles [14]. Reaction of chromone (1) with malononitrile in boiling ethanol containing one drop of triethylamine (TEA) as a basic catalyst produces (4E)-2-amino-3-cyano6H-benzoxocin-6-one (2) (Fig. 1). Formation of compound 2 may proceed via nucleophilic attack of malononitrile at $\mathrm{C}-2$ position of chromone (1) [1,4-micheal addition; intermediate A] followed by retro-michael reaction producing open chain intermediate B which undergoes an intramolecular nucleophilic addition of the phenolic $\mathrm{OH}$ group onto the nitrile function [intermediate $\mathrm{C}$ ] with concomitant proton transfer to produce the final product 2 as depicted in Fig. 1. The net result of this reaction is the enlargement of $\gamma$-pyrone ring in chromone (1) into oxocinone ring. The IR spectrum of compound 2 (Fig. 2) shows the presence of characteristic bands at $3443 \mathrm{~cm}^{-1}, 3326 \mathrm{~cm}^{-1}$ and $3212 \mathrm{~cm}^{-1}$, as observed by Ibrahim [13].

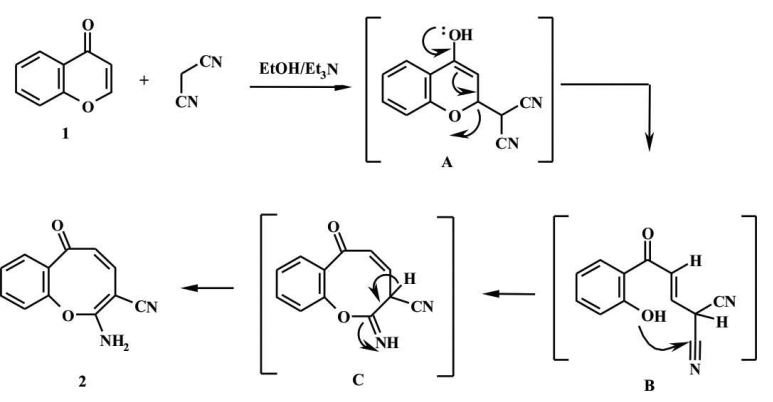

Fig. 1. The proposed mechanism for the formation 4(E)-ACBO.

\subsection{Structural analysis}

Fig. 3 shows the XRD pattern for the powder of 4(E)-ACBO recorded using Philips X-ray 


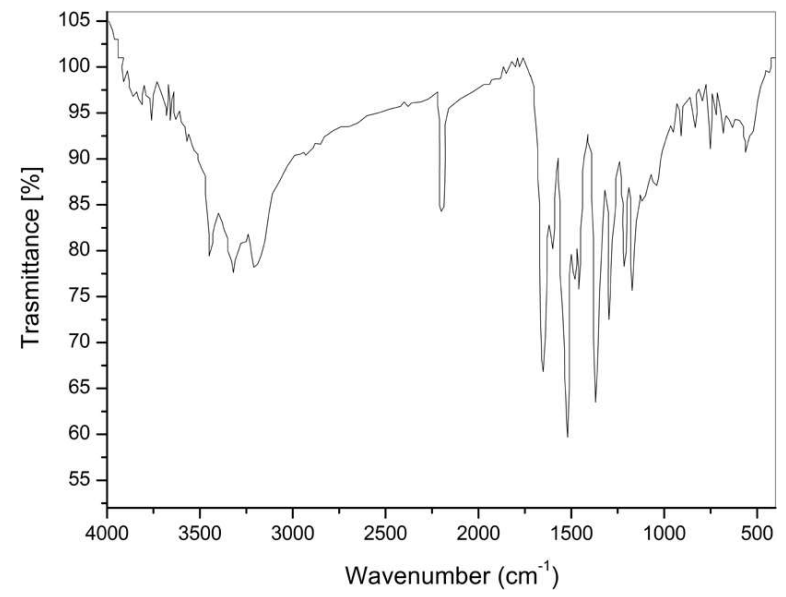

Fig. 2. IR spectrum for the powder of 4(E)-ACBO.

diffractometer. The diffraction lines in the pattern exhibit different intensities. Thus, the powder of 4(E)-ACBO has a polycrystalline nature. The obtained XRD data has been analyzed using the CRYSFIR computer program [15] to determine the unit cell and cell parameters of 4(E)-ACBO for the first time. The results show that the powder of 4(E)-ACBO has a triclinic unit cell structure with the lattice constants: $\mathrm{a}=9.664 \AA, \mathrm{b}=11.274 \AA$, $\mathrm{c}=19.719 \AA, \alpha=84.64^{\circ}, \beta=124.08^{\circ}, \gamma=81.02^{\circ}$ and space group $=\mathrm{P}-1$. Then, using the CHECKCELL program [16], the Miller indices ( $\mathrm{h} \mathrm{k} \mathrm{l)} \mathrm{were}$ calculated and listed in Table 1. Table 1 shows also the calculated values of the distance between atomic layers in a crystal, $\mathrm{d}$ and Bragg's angle, $\theta^{\circ}$ in comparison with that recorded experimentally from the data of X-ray diffraction for 4(E)-ACBO.

\subsection{Dielectric properties and AC conduc- tivity}

The dielectric properties and AC conductivity of bulk 4(E)-ACBO in the pellet form were measured as a function of frequency in the range of $42 \mathrm{~Hz}$ to $5 \mathrm{MHz}$ and at different temperatures ranging from $303 \mathrm{~K}$ to $373 \mathrm{~K}$. The complex dielectric constant, $\varepsilon^{*}$, of a material is represented by two parts as [17]:

$$
\varepsilon^{*}(\omega)=\varepsilon_{1}(\omega)-j \varepsilon_{2}(\omega)
$$

where $\omega$ is the angular frequency $(\omega=2 \pi f$ and $\mathrm{f}$ is the frequency of the applied field), $\varepsilon_{1}$ is the real part

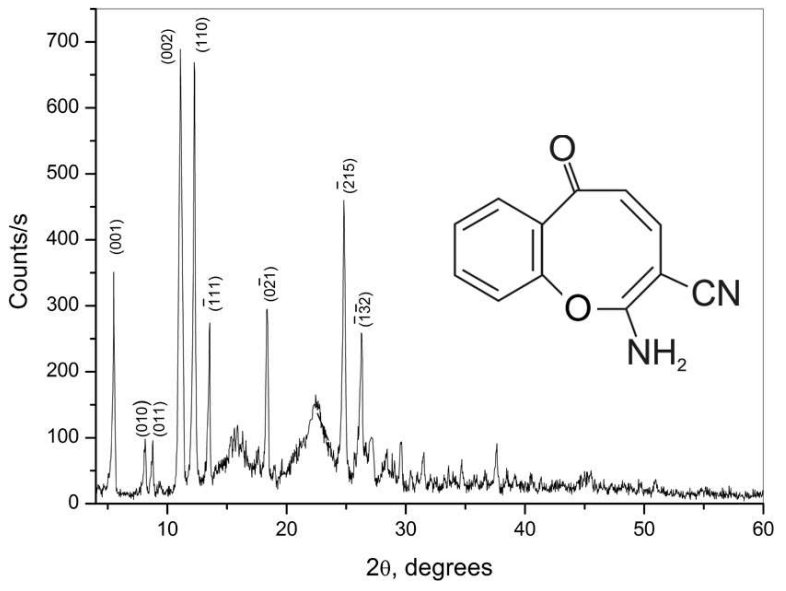

Fig. 3. XRD pattern for the powder of 4(E)-ACBO.

(dielectric constant) and $\varepsilon_{2}$ the imaginary part (dielectric loss). The real part of the complex dielectric constant is a measure of energy stored from the applied electric field in the material and identifies the strength of alignment of dipoles in the dielectric. The imaginary part of the complex dielectric constant is the energy dissipated in the dielectric which is associated with frictional dampening that prevents the displacement of bound charge from keeping in phase with the changing field $[18,19]$. The dielectric constant, $\varepsilon_{1}$, was calculated using the relation $[20,21]$ :

$$
\varepsilon_{1}=\frac{C d}{\varepsilon_{o} A}
$$

where $\mathrm{C}$ is the capacitance of the sample, $\mathrm{d}$ is the sample thickness, $\varepsilon_{\mathrm{o}}$ is the free space permittivity and $\mathrm{A}$ is the sample cross-sectional area. Fig. 4 shows the variation of $\varepsilon_{1}$ as a function of frequency at different temperatures for the pellet of 4(E)-ACBO. From the figure, we can see that $\varepsilon_{1}$ values decrease with the increase in frequency for all temperatures in the investigated range. First, at low frequencies, $\varepsilon_{1}$ shows a strong frequency dependence, especially at higher values of temperatures. Then, at higher frequency, the values of $\varepsilon_{1}$ are approximately constant for a certain value of temperature. When the applied field frequency is increased, the dipoles are no longer able to rotate rapidly, so that their oscillations begin to lag behind those of the field. As the frequency is further elevated, the dipoles are completely unable 
Table 1. Results of XRD data analysis for the powder of 4(E)-ACBO.

\begin{tabular}{ccccccc}
\hline No. & $\mathrm{d}_{\text {measured }}[\AA]$ & $2 \theta^{\circ}$ measured & Int. \% & $\mathrm{d}_{\text {calculated }}[\AA]$ & $2 \theta^{\circ}$ calculated & $\mathrm{h} \mathrm{k}$ l \\
\hline \hline 1 & 16.03009 & 5.50849 & 45.84 & 15.928 & 5.544 & 001 \\
2 & 10.86465 & 8.13111 & 9.23 & 10.86 & 8.134 & 010 \\
3 & 10.07893 & 8.76619 & 9.66 & 10.069 & 8.775 & 011 \\
4 & 7.96988 & 11.09246 & 96.41 & 7.964 & 11.101 & 002 \\
5 & 7.21247 & 12.26157 & 100.00 & 7.228 & 12.235 & 110 \\
6 & 6.55995 & 13.48665 & 38.3 & 6.584 & 13.437 & $\overline{1} 11$ \\
7 & 5.76672 & 15.35226 & 13.68 & 5.764 & 15.358 & 101 \\
8 & 5.67168 & 15.61111 & 12.84 & 5.665 & 15.63 & 110 \\
9 & 5.56889 & 15.90110 & 10.81 & 5.526 & 16.024 & 021 \\
10 & 5.41909 & 16.34364 & 12.31 & 5.43 & 16.31 & 020 \\
11 & 5.03443 & 17.60192 & 6.52 & 5.034 & 17.602 & 022 \\
12 & 4.82352 & 18.37810 & 43.69 & 4.824 & 18.375 & $0 \overline{2} 1$ \\
13 & 4.14391 & 21.42515 & 12.46 & 4.148 & 21.405 & $\overline{2} 13$ \\
14 & 3.94962 & 22.49254 & 19.69 & 3.947 & 22.51 & $\overline{2} 14$ \\
15 & 3.58944 & 24.78365 & 62.81 & 3.577 & 24.872 & $\overline{2} 15$ \\
16 & 3.46121 & 25.71730 & 6.34 & 3.461 & 25.721 & 211 \\
17 & 3.38871 & 26.27727 & 36.29 & 3.388 & 26.279 & $\overline{1} \overline{3} 2$ \\
18 & 3.29111 & 27.07107 & 11.45 & 3.292 & 27.064 & $\overline{2} 22$ \\
19 & 3.14139 & 28.38771 & 6.42 & 3.149 & 28.318 & $\overline{1} 16$ \\
20 & 3.01593 & 29.59503 & 8.69 & 3.017 & 29.589 & 114 \\
21 & 2.8388 & 31.48723 & 6.25 & 2.842 & 31.452 & $\overline{1} 35$ \\
22 & 2.38943 & 37.61255 & 7.08 & 2.389 & 37.616 & 321 \\
\hline & & & & & &
\end{tabular}

to folow the field and the orientation polarization vanishes. So, $\varepsilon_{1}$ begins to decrease reaching a constant value at higher values of frequency due to the space charge polarization only [22-24].

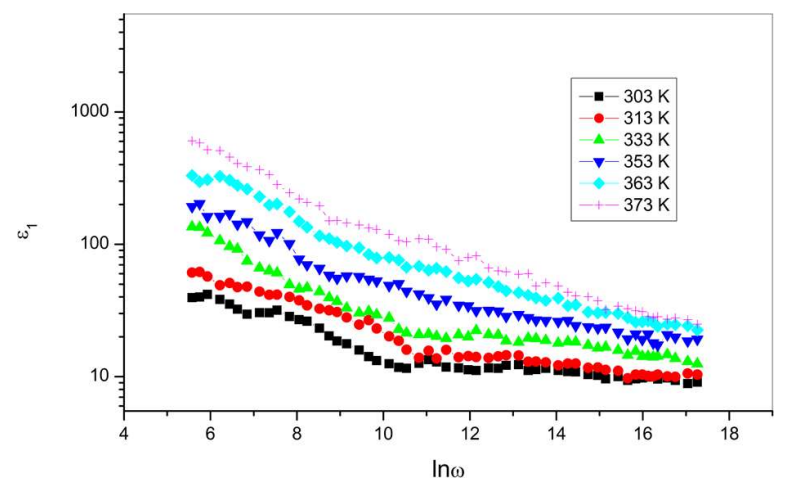

Fig. 4. Frequency dependence of dielectric constant, $\varepsilon_{1}$, for bulk 4(E)-ACBO at different temperatures.

The $\varepsilon_{1}$ values, in Fig. 4, also increase with increasing temperature at a certain value of frequency. At low temperature, the dipoles cannot orient themselves. When the temperature is increased the orientation of the dipoles is facilitated and this increases the value of orientational polarization, which leads to an increase of $\varepsilon_{1}$ with temperature $[25,26]$.

The dielectric loss, $\varepsilon_{2}$, was calculated from the relation [21, 27]:

$$
\varepsilon_{2}=\varepsilon_{1} \tan \delta
$$

where $\delta=90-\varphi$, and $\varphi$ is the phase angle which was measured using the LCR bridge. Fig. 5 shows the variation of $\varepsilon_{2}$ as a function of frequency at different temperatures for the pellet of 4(E)-ACBO. It is observed from the figure that $\varepsilon_{2}$ exhibits strong temperature dependence at higher temperature and lower frequencies. The higher value of $\varepsilon_{2}$ at low frequency is due to the free charge motion within the material [28]. 


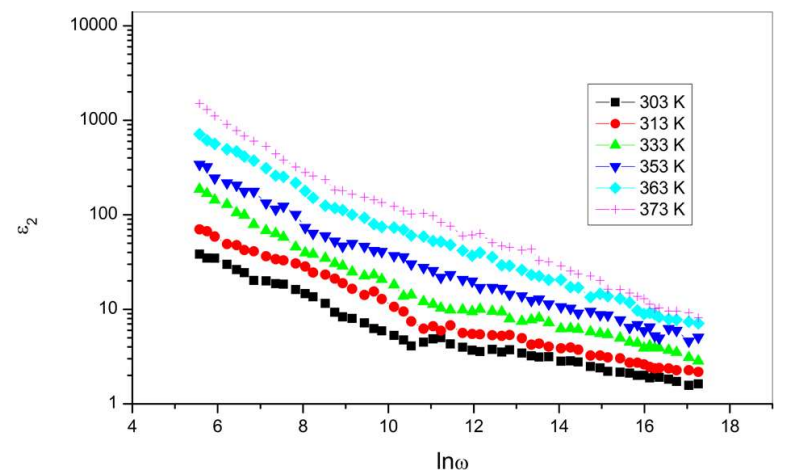

Fig. 5. Frequency dependence of dielectric loss, $\varepsilon_{2}$, for bulk 4(E)-ACBO at different temperatures.

AC conductivity, $\sigma_{\mathrm{AC}}(\omega)$, was evaluated from dielectric data, which related to the dielectric constant, in accordance with the following relation [28, 29]:

$$
\sigma_{A C}(\omega)=\varepsilon_{o} \omega \varepsilon_{2}
$$

Fig. 6 shows the frequency dependence of AC conductivity for 4(E)-ACBO at different temperatures. It is noticed from the figure that $\sigma_{\mathrm{AC}}(\omega)$ increases with the frequency and satisfies the law power relation [30, 31]: $\sigma_{\mathrm{AC}}(\omega)=\gamma \omega^{\mathrm{s}}$, where $\gamma$ is a constant depending on temperature and $s$ is the frequency exponent, $\mathrm{s} \leqslant 1$. Values of $\mathrm{s}$ were calculated from the slope of the linear plot of $\ln \sigma_{\mathrm{AC}}(\omega)$ with ln $\omega$ in Fig. 6 for each temperature.

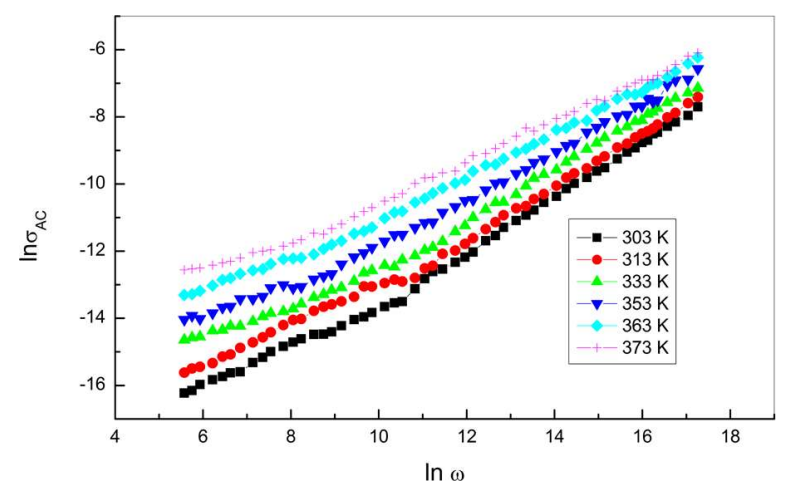

Fig. 6. Frequency dependence of AC conductivity, $\sigma_{\mathrm{AC}}$, for bulk 4(E)-ACBO at different temperatures.

The temperature dependence of $\mathrm{s}$ indicates the nature of the mechanism for $\mathrm{AC}$ conduction in $4(\mathrm{E})-\mathrm{ACBO}$. The variation of s against temperature is shown in Fig. 7. It shows that the values of s decrease with increasing temperature. This behavior can be explained in terms of the correlated barrier hopping $(\mathrm{CBH})$ model $[22,32]$ for conduction as observed in other organic compounds [22, 33, 34]. According to $\mathrm{CBH}$ model, the charge carrier hops between the sites (charged defect states) over the potential barrier separating them and the frequency exponent $\mathrm{s}$ can be written as [30]:

$$
s=1-\frac{6 k T}{W_{M}+k T \ln \left(\omega \tau_{o}\right)}
$$

where $\mathrm{k}$ is the Boltzmann's constant, $\mathrm{W}_{\mathrm{M}}$ is the maximum barrier height at infinite intersite separation and $\tau_{\mathrm{o}}$ is characteristic relaxation time. A first approximation of this equation gives the simple expression for the frequency exponent. Thus, $\mathrm{s}$ can be written as [35]:

$$
s=1-\frac{6 k T}{W_{M}}
$$

Substituting the obtained values of $\mathrm{s}$ in equation 6 , values of $\mathrm{W}_{\mathrm{M}}$ were estimated at different temperatures and listed in Table 2. It shows that $\mathrm{W}_{\mathrm{M}}$ values decrease with the increase in temperature.

Table 2. Values of $\mathrm{W}_{\mathrm{M}}, \mathrm{W}_{\mathrm{H}}$ and $\tau$ for bulk $4(\mathrm{E})$ - $\mathrm{ACBO}$ at different temperatures.

\begin{tabular}{cccc}
\hline $\mathrm{T}[\mathrm{K}]$ & $\mathrm{W}_{\mathrm{M}}[\mathrm{eV}]$ & $\mathrm{W}_{\mathrm{H}}[\mathrm{eV}]$ & $\tau[\mathrm{s}]$ \\
\hline \hline 303 & 0.607 & 0.152 & $3.334 \times 10^{-10}$ \\
313 & 0.539 & 0.135 & $1.475 \times 10^{-10}$ \\
333 & 0.532 & 0.133 & $1.031 \times 10^{-10}$ \\
353 & 0.527 & 0.131 & $7.591 \times 10^{-11}$ \\
363 & 0.488 & 0.122 & $4.917 \times 10^{-11}$ \\
373 & 0.461 & 0.115 & $3.599 \times 10^{-11}$ \\
\hline
\end{tabular}

The relaxation time $\tau$ for electrons to hop over a barrier of height $\mathrm{W}_{\mathrm{H}}$ is given as $[30,36,37]$ :

$$
\tau=\tau_{o} e^{\left(W_{H} / k T\right)}
$$

In the model of electrons transfer by thermal activation between two sites, each having a columbic potential well associated with it, which was proposed by Pike [35], the columbic wells of the neighboring sites overlap [30], and lower the effective barrier height from the value $\mathrm{W}_{\mathrm{M}}$ to of $\mathrm{W}_{\mathrm{H}}$ where 


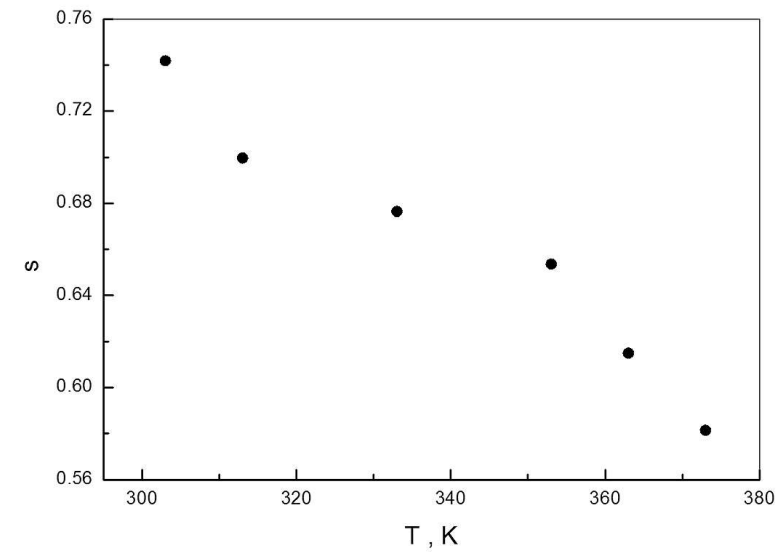

Fig. 7. Temperature dependence of the frequency exponent, s.

the condition $\left(\mathrm{W}_{\mathrm{H}} / \mathrm{W}_{\mathrm{M}}\right)<1 / 2$ is satisfied [35]. For relatively high strength of the overlap, the value of $\mathrm{W}_{\mathrm{H}}$ reduces to $1 / 4 \mathrm{~W}_{\mathrm{M}}[23,38]$. The values of $\mathrm{W}_{\mathrm{H}}$ and $\tau$ decrease with the increase in temperature as given in Table 2.

The temperature dependence of the AC conductivity $\left(\sigma_{\mathrm{AC}}\right)$ can be written as follows [22]:

$$
\sigma_{A C}=\sigma_{o} e^{\left(\Delta E_{A C} / k T\right)}
$$

where $\sigma_{\mathrm{O}}$ is a pre-exponential factor and $\Delta \mathrm{E}_{\mathrm{AC}}$ is the activation energy for $\mathrm{AC}$ conduction. The AC conductivity of 4(E)-ACBO was measured in a temperature range of $303 \mathrm{~K}$ to $373 \mathrm{~K}$. Fig. 8 shows the temperature dependence of $\sigma_{\mathrm{AC}}$ at different frequencies. From the figure, $\sigma_{\mathrm{AC}}$ increases with an increase in temperature, which indicates that the AC conductivity is a thermally activated process from the different localized states in the gap or its tails. The values of AC activation energy were calculated from the slope of the straight lines in Fig. 8 at different frequencies and are tabulated in Table 3. It is observed that $\Delta \mathrm{E}_{\mathrm{AC}}$ decreases with an increase in frequency. The increase in the applied field frequency enhances the electronic jump between the localized states, consequently the activation energy $\Delta \mathrm{E}_{\mathrm{AC}}$ decreases with increasing frequency $[19,21]$. This result confirms that hopping conduction is the dominant current transport mechanisms. The same behavior was obtained for other similar systems [22, 39].

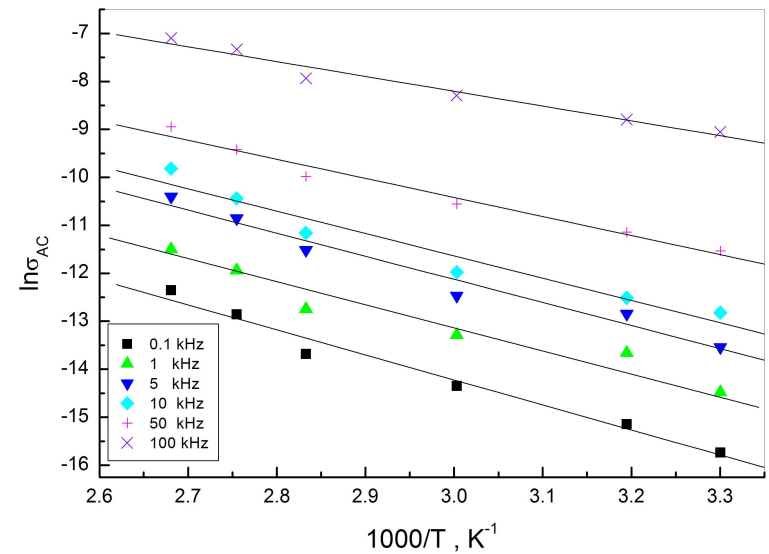

Fig. 8. Temperature dependence of AC conductivity, $\sigma_{\mathrm{AC}}$, for bulk $4(\mathrm{E})-\mathrm{ACBO}$ at different frequencies.

Table 3. Value of $\Delta \mathrm{E}_{\mathrm{AC}}$ for bulk $4(\mathrm{E})-\mathrm{ACBO}$ at different frequencies.

\begin{tabular}{ccccccc}
\hline $\mathrm{f}[\mathrm{kHz}]$ & 0.1 & 1 & 5 & 10 & 50 & 100 \\
\hline \hline$\Delta \mathrm{E}_{\mathrm{AC}}[\mathrm{eV}]$ & 0.449 & 0.422 & 0.415 & 0.402 & 0.342 & 0.266 \\
\hline
\end{tabular}

\section{Conclusion}

The XRD study revealed that the powder of $4(\mathrm{E})-\mathrm{ACBO}$ is a polycrystalline material and has a triclinic unit cell structure with $\mathrm{a}=9.664 \AA$, $\mathrm{b}=11.274 \AA, \mathrm{c}=19.719 \AA, \alpha=84.64^{\circ}$, $\beta=124.08^{\circ}, \gamma=81.02^{\circ}$. Both dielectric constant and dielectric loss decrease with increasing frequency and increase with increasing temperature in the investigated range. The values of the frequency exponent (s) were found to be temperature dependent, decreasing with increasing temperature. This confirmed the applicability of the correlated barrier hopping model. The values of the relaxation time $(\tau)$ decreased with the increase in temperature. The values of the activation energy for AC conduction decreased with increasing frequency. Such a decrease confirms that hopping conduction is the dominant mechanism.

\section{References}

[1] Jash S.K., Brahmacharic G., J. Org. Biomol. Chem., 1 (2013), 65.

[2] Dubey R.K., DiXit P., Arya S., IJIRSET, 3 (2014), 8141.

[3] Pao Y.J., Krupadanam G.L.D., Indian J. Chem. Techn., 39B (2000), 610. 
[4] Ibrahim M.A., Hassanin H.M., Alnamer Y.A., Synth. Commun., 44 (2014), 3470.

[5] Ibrahim M.A., El-Gohary N.M., Heterocycles, 89 (2014), 413.

[6] Ibrahim M.A., Ali T.E., El-Gohary N.M., ElKAZAK A.M., Eur. J. Chem., 4 (2013), 311.

[7] Ibrahim M.A., J. Brazil. Chem. Soc., 24 (2013), 1754.

[8] Ibrahim M.A., Synthetic Commun., 39 (2009), 3527.

[9] Yang Shu-Wen, Elangovan A., Ho Tong-Ing, Photoch. Photobio. Sci., 4 (2005), 327.

[10] Hendi A.A., Aust. J. Basic Appl. Sci., 5 (2011), 380.

[11] Anwar M., Ghauri I.M., Siddigi S.A., J. Phys. Condens. Mat., 50 (2005), 763.

[12] Senturk E., J. Solid State Chem., 177 (2004), 1508.

[13] Ibrahim M.A., Arkivoc, XVII (2008), 192.

[14] KRZYSZTOF K., CAS, 72 (1972), 128468n.

[15] ShIRlEY R., The CRYSFIRE System for Automatic Powder Indexing: User's Manual, Lattice Press, Guildford, 2000.

[16] Laugier J., Bochu B., LMGP - Suite of Programs for the Interpretation of X-ray Experiments, Grenoble, 2000.

[17] Mohamme M.I., Abd-Rabo A.S., Mahmoud E.A., Egypt. J. Solid., 25 (2002), 49.

[18] Ataseven T., Tataroglu A., Chinese Phys. B, 22 (2013), 117310.

[19] Ertugrul R., Tataroglu A., Chinese Phys. Lett., 29 (2012), 077304.

[20] Mumtaz M., Khan N.A., Khan S., J. Appl. Phys., 111 (2012), 013920-1.

[21] Ali H.A.M., Soliman H.S., SaAdeldin M., Sawaby K., Mat. Sci. Semicon. Proc., 18 (2014), 141.

[22] El-Nahass M.M., Ali H.A.M., Solid State Commun., 152 (2012), 1084.
[23] Darwish A.A.A., El-Nahass M.M., BeKheet A.E., J. Alloy. Compd., 586 (2014), 142.

[24] Tareev B., Physics of Dielectric Materials, Mir Publishers, Moscow, 1975.

[25] El-Mallah H.M., Acta Phys. Pol. A, 122 (2012), 174.

[26] El-Nahass M.M., El-DeEb A.F., AbD-Elsalam, Org. Electron., 7 (2006) 261.

[27] Hashem H.A., Abouelhassan S., Chinese J. Phys., 43 (2005), 955.

[28] Pradhan D.K., Choudhary R.N.P., SAManTARAY B.K., Int. J. Electrochem. Sc., 3 (2008), 597.

[29] Shakir M., Singh B.K., GaUr R.K., Kumar B., Bhagavannarayana G., Wahab M.A., Chalcogenide Lett., 6 (2009), 655.

[30] Elliott S.R., Adv. Phys., 36 (1987), 135.

[31] Long A.R., Adv. Phys., 31 (1982), 553.

[32] Elliott S.R., Philos. Mag. B, 36 (1977), 1291.

[33] Yakuphanoglua F., Aydogdu Y. SchatzchneIDer U., Rentschler E., Physica B, 334 (2003), 443.

[34] Haribat S.M., Kitaneh R.M.-L., AbU-Samreh M.M., SAlEH A.M., J. Semicond., 34 (2013), 112001.

[35] Pike G.E., Phys. Rev. B, 6 (1972), 1572.

[36] Bhatnagar V.K. Bhatia K.L., J. Non-Cryst. Solids, 119 (1990), 214.

[37] Mohamed R.I., Gadou A.M., Egypt. J. Solid., 23 (2002), 277.

[38] Mott N.F., Davis E.A., Street R.A., Philos. Mag., 32 (1975), 961.

[39] Darwish A.A.A., Hassanien A.M., Hanafy T.A., EL-NAHASs M.M., Synthetic Met., 199 (2015), 339.

Received 2015-10-16 Accepted 2016-02-15 